\title{
Landscape Pattern Impacts on the Population Density and Distribution of Black Shama (Copsychus cebuensis Steere) in Argao Watershed Reserve, Argao, Cebu, Philippines
}

\author{
Archiebald Baltazar B. Malaki, ${ }^{1}$ Rex Victor O. Cruz, ${ }^{2}$ Nathaniel C. Bantayan, ${ }^{2}$ \\ Diomedes A. Racelis, ${ }^{2}$ Inocencio E. Buot Jr., ${ }^{3}$ and Leonardo M. Florece ${ }^{4}$ \\ ${ }^{1}$ Cebu Technological University, Cebu Campus, Argao 6021, Cebu, Philippines \\ ${ }^{2}$ Institute of Renewable and Natural Resources, College of Forestry and Natural Resources, University of the Philippines Los Banos, \\ Laguna 4031, Philippines \\ ${ }^{3}$ Institute of Biological Sciences, College of Arts and Sciences and School of Environmental Science \& Management (SESAM), \\ University of the Philippines Los Banos, Laguna 4031, Philippines \\ ${ }^{4}$ School of Environmental Science and Management, University of the Philippines Los Banos, Laguna 4031, Philippines
}

Correspondence should be addressed to Archiebald Baltazar B. Malaki; archlam68@yahoo.com

Received 3 May 2013; Accepted 23 June 2013

Academic Editors: I. Bisht, P. De los Ríos Escalante, and R. Rico-Martinez

Copyright (C) 2013 Archiebald Baltazar B. Malaki et al. This is an open access article distributed under the Creative Commons Attribution License, which permits unrestricted use, distribution, and reproduction in any medium, provided the original work is properly cited.

\begin{abstract}
This study determined the impacts of landscape pattern on population density of $C$. cebuensis within AWR, a conservation priority in Cebu, Philippines. Three land uses were identified, namely, (a) cultivated (3,399 ha/45\%); (b) forestlands (3,002 ha/40\%); and (c) build-up (1,050 ha/15\%). Forest patches at class have irregular/complex shapes; thus the forest areas in AWR are more fragmented and heterogeneous. Estimated population density of C. cebuensis was 52 and 53 individuals per hectare in mixed and natural forests. There were only three predictors at the landscape and four at the sampling site level, respectively have able to explain the behavior of the population density of C. cebuensis. Relative humidity and canopy cover were having high positive significant correlations while tree basal area has high negative correlation (at landscape). Elevation and canopy cover have positive high significant and significant correlations, while slope and shrub cover have negative significant correlation with C. cebuensis population density. The adjusted $R^{2}$ values were 0.345 and 0.212 (at landscape and sampling site). These suggest that about $34.5 \%$ of the variations of the population density of C. cebuensis have been accounted for by the former and only $21.2 \%$ by the latter. Preservation and protection of remaining forest fragments within AWR are paramount.
\end{abstract}

\section{Introduction}

Landscape ecology explains landscape pattern and interprets its possible ecological impacts particularly on energy and material flow on flora and fauna found at the landscape [1]. Argao watershed is currently experiencing these various changes that threaten biodiversity. It is located at the southeastern part of Cebu, Philippines. Some of the limited natural forest patches of the watershed are sporadically distributed on upland barangays, which are pervasively threatened from sustained illegal cutting of trees, fuel wood gathering, and converting forest to other land uses such as agriculture [2].
In 2001, the International Union for the Conservation of Nature (IUCN) declared Mt. Lantoy, which is located within Argao watershed reserve (AWR), as 71st of the 117 Important Bird Areas (IBA) in the country [3], because of the presence of endangered Cebu Black Shama (Copsychus cebuensis) and Cebu Flowerpecker (Dicaeum quadricolor).

C. cebuensis is an endemic bird species to the island of Cebu in the Philippines. It has always been considered rare and endangered as it has very small range and population [3]. Conducting detailed ecological research to determine threats and their level of impact, as a case study in Argao watershed (AWR), will facilitate conservation planning and 
Cebu PAGASA complex $(23 \mathrm{~m})$

[35-35]

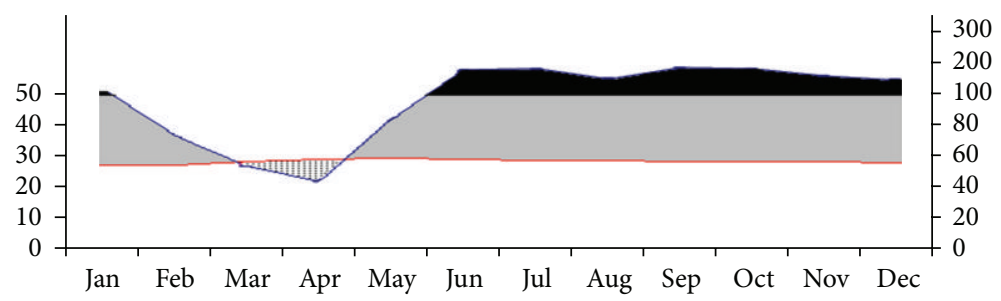

FIGURE 1: Climogram for Mactan, Cebu, showing average monthly temperature and rainfall data from 1973 to 2007. Climatic data were taken from PAGASA, Mactan [11].

management. The study examined impacts of landscape pattern in AWR on the population density and distribution of $C$. cebuensis. Emphasis on: (1) area distribution of different landscape elements constituting AWR; (2) analyzed landscape pattern or structure in AWR; (3) determined the relationship between landscape variables and population density and distribution of C. cebuensis in AWR.

\section{Materials and Methods}

\subsection{Description of the Study Site}

2.1.1. Topography and Slope. The general topography of the area is steep to very steep, with rugged terrain ranging from $12 \%$ to $60 \%$ slope in any direction [4]. The highest elevation is about $1,000 \mathrm{~m}$ above sea level which is located in Barangay Ablayan, Dalaguete, Cebu, in the southwestern part of the watershed where headwaters emanate. On the other hand, one of the highest mountain peaks within the watershed area is situated in Mt. Lantoy in Barangay Tabayag, Argao, with an elevation of about $593 \mathrm{~m}$ above sea level.

2.1.2. Climatic Type. The climate at AWR is classified under Climate Type III. Rainy season is from May up to November, while dry season is from December to April. Figure 1 shows the climogram of Mactan, Cebu, the nearest weather station to AWR. The figure shows the average monthly temperature and rainfall data from 1973 to 2007. The dotted area represents the dry period. The wet season is represented by the grayshaded area, with rainfall less than $100 \mathrm{~mm}$, and black area, with rainfall more than $100 \mathrm{~mm}$.

2.1.3. Vegetative Cover and Land Use. The area has two different types of forest cover: the naturally grown trees which are indigenous or native species and the man-made forest which is the plantation, previously managed under Southern Cebu Reforestation Development Project (SCRDP) in the early 1970s. Some remnants of natural forest fragments are found at the peak of Mt. Lantoy and at the slopes of Argao River. Isolated forest patches are still present in barangays Canbantug, Panadtaran, Usmad, Tabayag, Conalum, and Cansuje. Mother trees of Ipil (Intsia bijuga (Colebr.) Kuntze) and Molave (Vitex parviflora Juss) are native to the area.
Natural vegetation and plantation forests comprise $29 \%$ (1,119.54 ha) of the watershed area [12]. Mahogany (Swietenia macrophylla) and Yemane (Gmelina arborea) are the two exotic species commonly planted in the plantation forest.

2.1.4. Collection/Procurement of Geographic Information System (GIS) Thematic Layers and Remotely Sensed (RS) Image. GIS thematic layers and RS image were obtained to be able to generate the land use and land cover of the study site as well as other watershed maps. These data were obtained from the National Mapping and Resource Information Authority or NAMRIA. NAMRIA provided three digital images like AVNIR, SPOT, and LANDSAT. Among these, the image from SPOT-5 was utilized for this study. SPOT-5 image was with $2.5 \mathrm{~m}$ resolution and taken 2006/2007 available during conduct of study. Other base maps were acquired from different agencies including DENR Regional Office-VII, CENRO-Argao, and LGU-Argao particularly CBRM Office.

2.1.5. Collecting/Gathering of Other Supplementary Information. Related information on the study topic was collected from the internet, especially in the directory of open online journal in the UP system to acquire published articles/materials, books, monograph, and journals, among others which were related to the present work.

\subsection{Examination of Areal Distribution of Different Land Use/Land Cover (LULC) Classes}

2.2.1. Land Use/Land Cover (LULC) Generation. This study utilized the RGB SPOT-5 satellite imagery, true color composites of bands 2, 1 , and 3 . This is a processed digital image of $2.5 \mathrm{~m}$, pixel size resolution taken in December 2006/2007, acquired at the National Mapping Resource Information Authority (NAMRIA), Taguig City, Metro Manila. All GIS simulation modeling was carried out using ARC/INFO software program version 10 [13], particularly in generating the land use/land cover classes (LULCC) of the study site. Supervised using maximum likelihood (ML), the algorithm was used in image classification. Then ground truthing or ground validation activities between the two simulation processes were conducted. 
2.2.2. Ground Truthing or Validation. High-resolution digital map like Google Earth was used, and actual study site visitation based on randomly GIS generated geographic coordinates was done to validate the images. This was important to clearly identify the areas covered by heavy clouds or shadows produced on the SPOT-5 satellite image.

2.2.3. Supervised Classification. This is a process used for the extraction of quantitative information from remotely sensed image data with the analyst having prior knowledge of the available classes. This process is performed after the completion of the ground truthing activities, where the information obtained from the latter is used as the basis for the supervised classification technique. Finally, the number of pixels and area for each class and the landscape metrics or indices using ArcGIS/Patch analyst extensions [14] were estimated, and the statistics for each class were shown in graphs and/or tables.

Figure 2 summarizes the foregoing processes.

\subsubsection{Area Distribution Analysis of Different Land Use/Land} Cover (LULC) Classes. To determine the areal distribution of the different LULC classes, the newly generated LULC map was used in the analysis as input. The area of each LULC class was determined using GIS, specifically the spatial analyst tools. Subsequently, the results were tabulated and qualitatively analyzed.

\subsection{Landscape Pattern Analysis (LPA)}

2.3.1. Landscape Metrics (LM) Selection. Table 1 summarizes the landscape metrics that were used in quantifying the landscape pattern (LP) in AWR. Specifically, shape metrics intend to measure landscape configuration (LC), where LC refers to the nature of shape of patches in certain class or the entire watershed landscape. It is also an overall measure of how complex or irregular the shape of all the patches is in a class or landscape [5].

2.3.2. Calculation and Analysis of Landscape Metrics (LM) or Indices. The newly generated LULC map of AWR was used as base map to generate and calculate LM or shape metrics using PATCH ANALYST extensions for ArcMap Version 4.2 [14]. The indices or metrics were calculated only at class level since fragmentation is best analyzed at this level rather than at the landscape [5]. Furthermore, the calculation for the percentage occupied by each class with respect to the entire watershed landscape was undertaken with an excel format. Subsequently, qualitative analysis of LP in AWR was undertaken on the basis of calculated metrics or indices value and available literature.

Equations used in the calculation of indices or metrics are as follows.

(1) Mean Shape Index (MSI). MSI is equal to 1 when all patches are circular (for polygons) or square (for rasters or grids), and it increases with increasing patch shape irregularity [5].

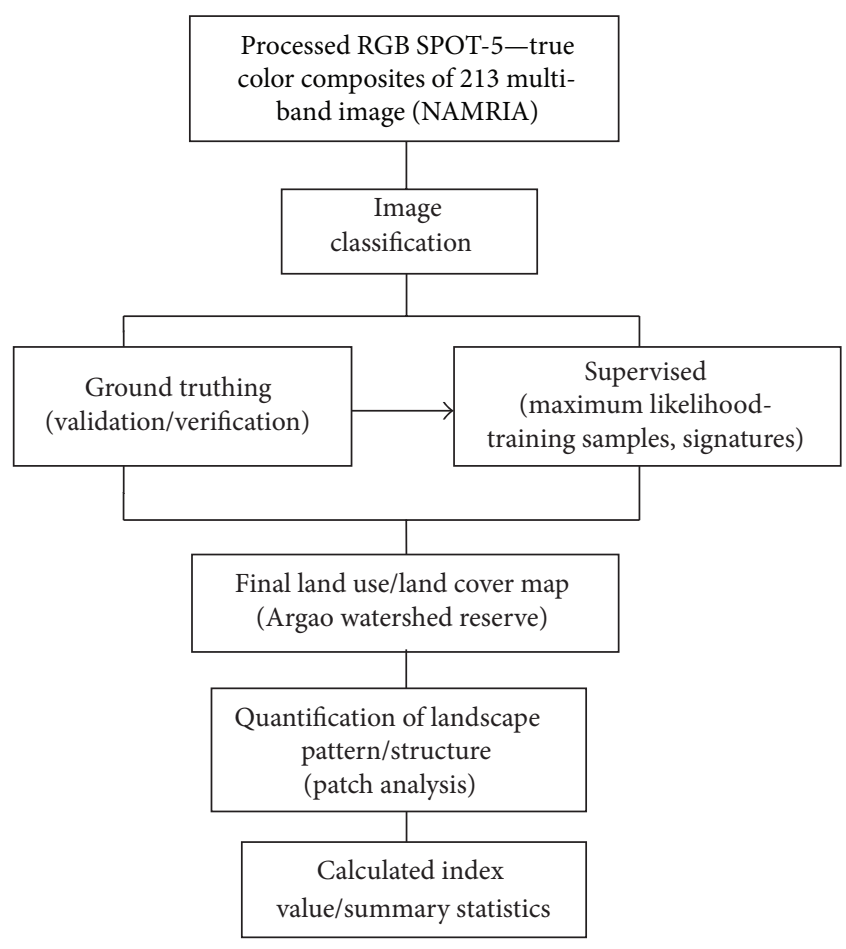

FIGURE 2: GIS simulation processes for land use/land cover classes generation in AWR.

\section{Consider}

$$
\mathrm{MSI}=\frac{1}{n} \sum_{j=1}^{n} \frac{\left(0.25 * p_{j}\right)}{\sqrt{a_{j}}},
$$

where $p_{j}$ is the perimeter of the $j$ th patch and $a_{j}$ is the area of the $j$ th patch.

(2) Area-Weighted Mean Shape Index (AWMSI). It is equal to 1 when all patches are circular (for polygons) or square (for rasters (grids)), and it increases with increasing patch shape irregularity [5].

Consider

$$
\text { AWMSI }=\sum_{j=1}^{n} \frac{0.25 p_{j}}{\sqrt{a_{j}}} \frac{a j}{a_{\text {total }}},
$$

where $p_{j}$ is thae perimeter of the $j$ th patch and $a_{j}$ is the area of the $j$ th patch. $a_{\text {total }}=$ is the summed area of all patches (Pn $\left.j^{1 / 4} 1 a_{j}\right)$.

(3) Mean Patch Fractal Dimension (MPFD). Index valueapproaches one for shapes with simple perimeters and approaches two when shapes are more complex [5].

Consider

$$
\text { FRAC }=\frac{2 \ln \left(0.25 p_{i j}\right)}{\ln a_{i j}},
$$

where $p_{i j}$ is the perimeter $(\mathrm{m})$ of patch $i j$ and $a_{i j}$ is the area $\left(\mathrm{m}^{2}\right)$ of patch $i j$. 
TABLE 1: Landscape metrics used in quantifying the landscape pattern in Argao watershed [5].

\begin{tabular}{lcl}
\hline Landscape metrics & Abbreviation & Description \\
\hline Shape metrics & & \\
(a) Mean shape index & MSI & Patch-level shape index averaged over all patches in the landscape \\
(b) Area-weighted mean shape index & AWMSI & Mean patch shape index weighted by relative patch size \\
(c) Mean patch fractal dimension & MPFD & The average fractal dimension of individual patches in the landscape \\
(d) Area-weighted mean patch fractal dimension & AWMPFD & The patch fractal dimension weighted by relative patch area \\
\hline
\end{tabular}

TABLE 2: List of landscape variables.

\begin{tabular}{|c|c|c|}
\hline Habitat variables & References & Methods of measurement \\
\hline \multicolumn{3}{|l|}{ (1) Physical features } \\
\hline (a) Altitude/elevation & Bibby et al. [6] & GPS receiver \\
\hline (b) Slope gradient & Bibby et al. [6] & Abney hand level \\
\hline (c) Aspect & Bibby et al. [6] & Compass \\
\hline (d) Distance/nearest streams/rivers & Bibby et al. [6] & Spatial Analyst (GIS) \\
\hline \multicolumn{3}{|l|}{ (2) Human disturbance } \\
\hline $\begin{array}{l}\text { (a) Dist. from sampling site to } \\
\text { forest edge/road }\end{array}$ & & Spatial analyst (GIS) \\
\hline $\begin{array}{l}\text { (b) Dist. from sampling site to a } \\
\text { nearest village/community }\end{array}$ & & Spatial analyst (GIS) \\
\hline (c) Dist. to agriculture/cultivation & & Spatial analyst (GIS) \\
\hline \multicolumn{3}{|l|}{ (3) Vegetation structures } \\
\hline (a) Total height $(\mathrm{TH})$ & Bibby et al. [6] & Haga \\
\hline (b) Diameter at breast height (DBH) & Bibby et al. [6]/Rosli et al. [7] & Diameter tape \\
\hline (c) Canopy density & Bibby et al. [6] & Densitometer \\
\hline (d) BA of trees/ha & Bibby et al. [6] & Computation/equation \\
\hline (e) Tree density/ha & Rosli et al. [7]/Posa and Sodhi [8] & Computation/equation \\
\hline (f) $\%$ shrub/herb cover & Rosli et al. [7]/Posa and Sodhi [8] & Computation/equation \\
\hline (g) Number of trees & Rosli et al. [7]/Posa and Sodhi [8] & Ocular observation \\
\hline (g.1) Diameter classes & & Frequency/counts \\
\hline (g.2) Height classes & & Tally/counts \\
\hline (h) Presence and absence of bamboo thickets & Kennedy et al. [9] & $\begin{array}{c}\text { Tally/counts } \\
\text { Occular observation }\end{array}$ \\
\hline (i) Diversity index $\left(H^{\prime}\right)$ & Shannon-Weaver [10] & $\begin{array}{c}(1=\text { presence; } 0=\text { absence }) \\
\text { Evenness index value }\end{array}$ \\
\hline \multicolumn{3}{|l|}{ (4) Microclimate } \\
\hline (a) Temperature & Rosli et al. [7]/Posa and Sodhi [8] & $\begin{array}{l}\text { Digital-min/max } \\
\text { thermohygrometer }\end{array}$ \\
\hline (b) Relative humidity & Rosli et al. [7]/Posa and Sodhi [8] & EasyViewDigital Light \\
\hline (c) Light intensity & Rosli et al. [7]/Posa and Sodhi [8] & Meter-Model EA30 \\
\hline
\end{tabular}

(4) Area-Weighted Mean Patch Fractal Dimension (AWMPFD). It is similar to mean patch fractal dimension with the addition of individual patch area weighting applied to each patch [5].

\subsection{Relationship between Landscape Variables and Population Density of C. cebuensis}

2.4.1. Landscape Variables ( $L V)$. To determine the relationship between landscape variables and population density of
C. cebuensis, field survey on the selected forest patches in Argao watershed was conducted. The landscape variables (LV) (Table 2) were broadly categorized into the following: (a) physical, (b) habitat disturbance, (c) vegetation, and (d) microclimate variables. Some of these variables were gathered simultaneously with the bird data, and some LV were gathered indirectly using field data as inputs and equations. Table 2 presents the variables that are considered in this study.

2.4.2. Bird Sampling. Data on the population density of C. cebuensis was collected during the breeding season 
of the target species using distance point count sampling method [6]. A total of 130 circular point count stations, 87 of which were mixed and 43 were natural forest, respectively, with 20 meter radius have been established among the four sampling areas: twenty-six (26) plots in Mt. Lantoy (Brgy. Tabayag), 23 plots in Brgy. Canbantug, 38 in Brgy. Usmad, and 43 plots in Brgy. Cansuje. At each point survey station, the target bird species detected (i.e., either seen or heard) within $20 \mathrm{~m}$ radius were recorded for about 10 minutes [15]. The distance of every C. cebuensis encountered was estimated when first detected and recorded. Other information also noted such as no. of clusters, time start, time observed, and type of contact, among others. The survey was conducted early in the morning and late in the afternoon (between $0600 \mathrm{H}$ to $1000 \mathrm{H}$ and $1600 \mathrm{H}$ to $1800 \mathrm{H}$, and no survey was conducted during bad weather especially during rainfall). This period of time is suitable as most of forest birds are active in the early morning and late in the afternoon. All point survey stations were visited just only one time during the whole study period from April 7 to May 28, 2012 (for almost 2-month period).

2.4.3. Regression Analysis. An enter method multiple regression analysis was applied to determine the relationship between the landscape variables ( 25 predictors were tested in the landscape level analysis and only 10 predictors were finally included in the sampling site) and population density of $C$. cebuensis using

$$
Y=Y=b_{0}+b_{1} X_{1}+b_{2} X_{2} \cdots+b_{q} X_{q}+\varepsilon,
$$

where $Y$ is the dependent variable (population density of C. cebuensis); $X_{1}, X_{2}, \ldots, X_{q}$ are the independent variables or predictors (landscape variables); $b_{0}, b_{1}, b_{2}, \ldots, b_{q}$ are the partial regression coefficients of independent variables or predictors; and $\varepsilon$ is the Random error.

All statistical analyses were undertaken with SPSS 11.5 license to UPLB College, Laguna, Philippines.

\section{Results and Discussion}

\subsection{Land Use/Land Cover (LULC) Analysis}

3.1.1. Land Use/Land Cover Map (LULCM). Figure 3 presents the newly generated land use/land cover of Argao watershed. As shown in Table 4 there were three landscape elements or land uses generated, namely, (a) cultivated areas with a total land area of about 3,399 ha or $45 \%$, (b) forest areas with an area of about 3,002 ha or $40 \%$, and (c) built-up areas with 1,050 ha or $15 \%$. It can be observed that AWR is dominated by cultivated areas followed by forest and builtup. This can be attributed to the fact that Argao watershed has higher human population living within and outside the perimeter of the watershed area. According to $[16,17]$ about 24,096 people (from the municipalities of Argao and Dalaguete) reside within the perimeter of AWR and about 108,646 people reside outside the watershed area [18]. In fact, Argao municipality was considered as one of the biggest municipalities in southern Cebu comprising 45 barangays, and these barangays are mostly located in the upland areas. In 2010 Argao has a population of 69,503 [16], while the municipality of Dalaguete has 63,239 [18].

The difference between cultivated and forest areas is only about 375 ha or $5 \%$. This figure may be considered as small fraction, yet this is, however, significant due to an increasing human population in the upland or in the watershed area as evident in the present population level. As population grows demand for watershed resources will likely grow especially areas devoted for cultivation or for agriculture, there might be an increasing encroachment into the remaining forest patches, there will be more land use conversion can be expected that would surely tantamount to further forest deforestation and degradation. Ultimately, this condition may seriously affect and would endanger native forest habitat for C. cebuensis and other natural resources in the watershed area.

\subsection{Landscape Pattern Analysis (Using Shape Metrics)}

(1) Area-Weighted Mean Shape Index (AWMSI). Figure 4 shows the calculated index values in AWMSI for three categories or classes. The results show that cultivated areas have the highest computed AWMSI of 65.45, followed by forest class with 15.49, and the lowest were built-up areas with 5.01. All calculated index values are greater than two which serve as benchmark values for patches having more complex and irregular shape [5]. These findings suggest that all three classes or categories have very irregular and/or complex patch shape. These could be attributed to the intense human activities especially in cultivated areas encroaching ultimately into forest areas as observed in this study, thereby exposing the latter to pasture or agriculture, microclimatic alterations that usually occur in the nearby surrounding forest edges through increased penetration of sunlight and wind.

(2) Mean Shape Index (MSI). Figure 5 shows the calculated index values for MSI for all three classes. It can be observed that built-up areas got the highest value of 1.53, while forest and cultivated areas have the same value of 1.39. It can be observed that the values for all the three classes greater than one indicate that the patch shape had increasing irregularity and complexity. This indicates a more fragmented and more heterogeneous watershed landscape [5]. Likewise, this can be attributed to the high level of human activities that usually occur along edges and within the forest interior (i.e., kaingin making, infrastructure development, and conversion of forest lands into other uses) which have been observed in the study.

(3) Mean Patch Fractal Dimension (MPFD). Figure 6 presents the computed index value for the three land use classes, of which forest areas had the highest value of 1.85 , followed by cultivated lands of 1.84 and built-up areas with 1.73 . It was observed that the value for three classes was greater than one and nearly approaches two, suggesting a more complex shape, high patch shape irregularity, and a highly fragmented watershed landscape. These findings further indicate that Argao watershed is more of an edged habitat which can bring impacts on the wildlife species especially forest-interior 


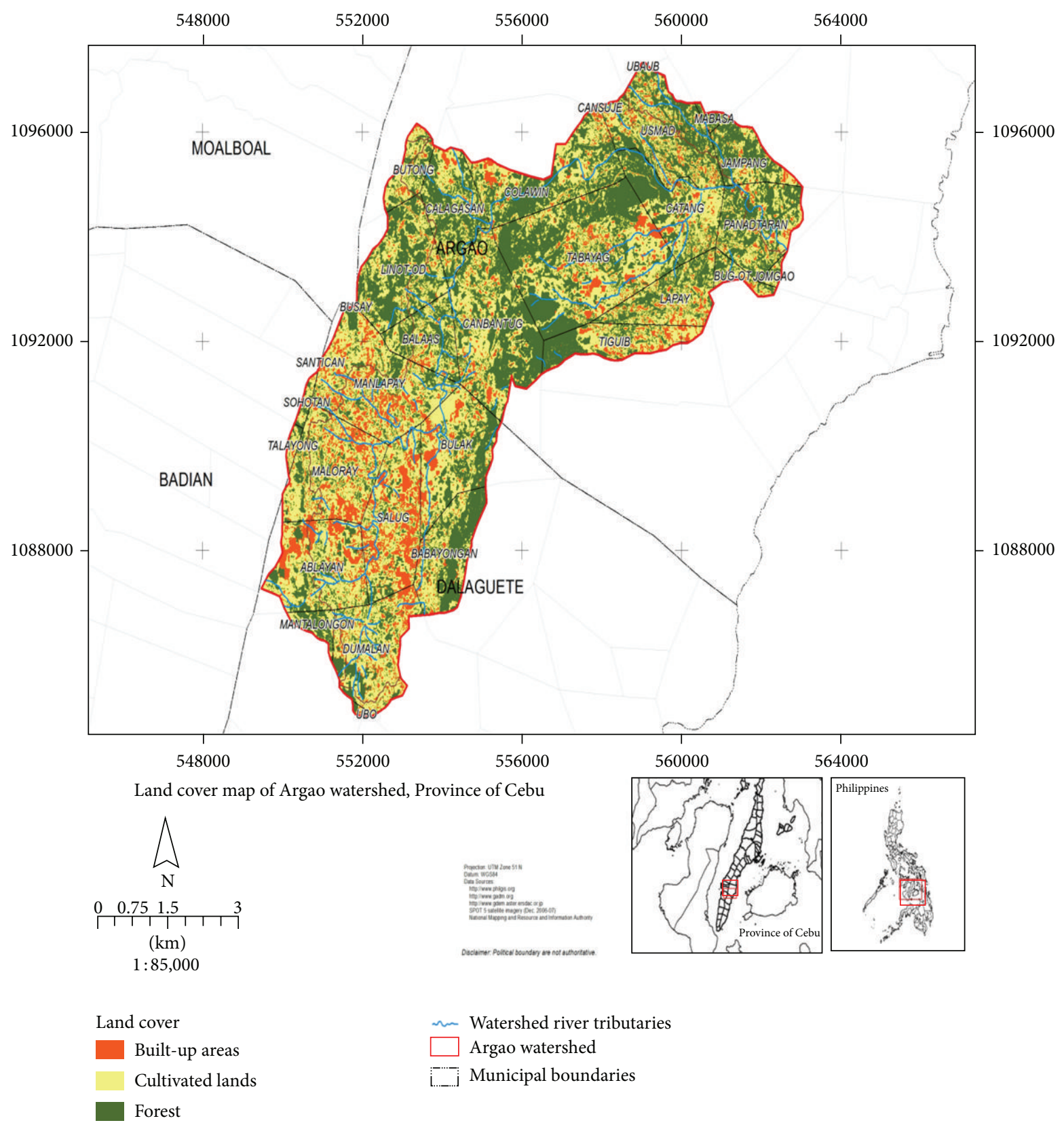

Figure 3: Newly generated land use/land cover map of AWR from SPOT-5. (Data sources: CENRO, Argao, 2003; CBRMP-LGU, Argao, Cebu, 1999; NAMRIA.)

species like most of insectivorous birds' especially C. cebuensis [19].

(4) Area-Weighted Mean Patch Fractal Dimension (AWMPFD). Figure 7 presents the results of the calculated index values for AWMPFD. It showed that cultivated areas got the highest index value of 1.65, while forest areas are on the second place of 1.57, and the lowest are built-up areas with 1.53. All the three values were greater than one and nearly close to two. These results suggest that the patch shapes of three classes were complex, further indicating that AWR had exposed edges, fragmented habitat, and patch shape that tend to be more irregular and complex and more heterogeneous.

\subsection{Relationship between Landscape Variables and Population Density of Copsychus cebuensis}

(1) Population Density Estimates for Habitat or Landscape Level (Mixed and Natural Forest). Table 3, however, presents the estimated population density of C. cebuensis (using DISTANCE 6 release 2 software program) for two habitat 
TABLE 3: Summary table for estimating population density on C. cebuensis.

\begin{tabular}{lcccc}
\hline Habitat/stratum & $\begin{array}{c}\text { Estimates } \\
(D)\end{array}$ & $\begin{array}{c}\text { Coefficient of } \\
\text { variation }(\% \mathrm{CV})\end{array}$ & $\begin{array}{c}\text { Degrees of } \\
\text { freedom }\end{array}$ & 95\% confidence interval \\
\hline Mixed forest & 52 & 10.70 & 163.71 & 42.161 \\
Natural forest & 53 & 10.71 & 164.12 & 64.250 \\
\hline
\end{tabular}

TABLE 4: Pooled density estimates of population density of C. cebuensis in four sampling locations.

\begin{tabular}{lcccc}
\hline $\begin{array}{l}\text { Sampling locations } \\
\text { (Barangay) }\end{array}$ & $\begin{array}{c}\text { Pooled density } \\
\text { estimates }(D)\end{array}$ & $\begin{array}{c}\text { Coefficient of variation } \\
(\text { CV-\% })\end{array}$ & $\begin{array}{c}\text { Degrees of freedom } \\
(\text { df })\end{array}$ & 95\% confidence interval \\
\hline Tabayag & 81.053 & 38.98 & 24.24 & 37.312 \\
Canbantug & 118.55 & 40.52 & 22.47 & 52.860 \\
Usmad & 114.15 & 20.42 & 42.18 & 265.87 \\
Cansuje & 118.61 & 18.21 & 50.18 & 75.921 \\
\hline
\end{tabular}

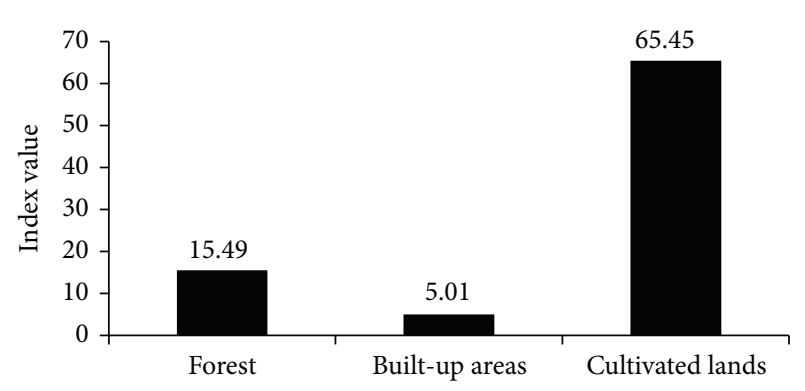

FIgure 4: Calculated index value for AWMSI at class level.

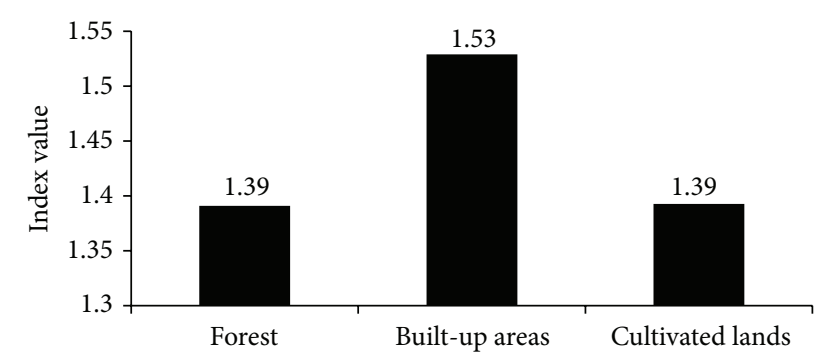

FIGURE 5: Calculated index value for MSI at class level.

types where mixed forest had 52 and 53 individuals $-\mathrm{ha}^{-1}$ for natural forest having the same coefficient of variation $(\mathrm{CV})$ of $10 \%$ at $95 \%$ confidence interval. It is noted that these two habitat types or strata have more or less equal in the density of population per unit area. This indicates that C. cebuensis may have been adapted to this type of habitat conditions in the watershed area where they inhabit. These findings further indicate that $C$. cebuensis are still widely distributed among the remaining forest habitat patches within Argao watershed despite of being highly fragmented and despite the fact that they highly disturb watershed landscape.

(2) Population Density Estimates at Sampling Sites. Among the sampling locations, Barangay Cabantug and Barangay Cansuje had the highest pooled population density estimate of C. cebuensis with 118 individuals $\mathrm{ha}^{-1}$ followed by Barangay Usmad with 114 individuals $-\mathrm{ha}^{-1}$, and the lowest is

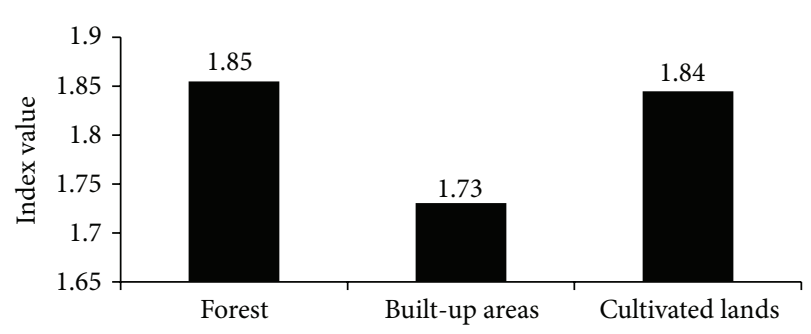

FIGURE 6: Calculated index value for MPFD at class level.

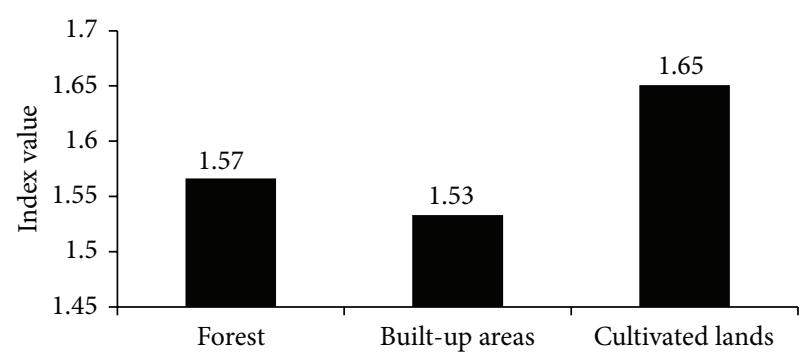

FIGURE 7: Calculated index value for AWMPFD at class level.

Barangay Tabayag with 81 individuals $-\mathrm{ha}^{-1}$ (Table 4). It can be observed that, though Barangay Canbantug and Barangay Cansuje have the same population density estimates, they had different $\% \mathrm{CV}$ of $40 \%$ and $18 \%$, respectively. It was observed further that the higher the number of contacts, the lower the $\% \mathrm{CV}$, whereas the lower the no. of contacts the higher $\% \mathrm{CV}$. According to [6], for a distance sampling method to be adapted especially in point count survey, it needs to have at least 80 to 100 individual contacts in order to achieve more reliable estimates of the density of population for certain organism under consideration. Based on these findings it can be inferred that the C. cebuensis are still widely distributed among the fragments of forest habitat patches remaining in Argao watershed.

(3) Regression Analysis between Landscape Variables and Population Density of C. cebuensis for Habitat or Landscape Level (Mixed and Natural Forest). Table 5 presents the results 
TABLE 5: Results of regression analysis between population density estimates of C. cebuensis at habitat level (with 25 predictors or landscape variables included).

\begin{tabular}{|c|c|c|c|c|c|c|}
\hline \multirow{2}{*}{ Model } & \multirow{2}{*}{$\begin{array}{l}\text { Predictors } \\
\text { (constant) }\end{array}$} & \multirow{2}{*}{ Code } & \multicolumn{2}{|c|}{ Unstandardized coefficients } & \multirow{2}{*}{$\begin{array}{c}\text { Standardized } \\
\text { coefficients } \\
\text { Beta }\end{array}$} & \multirow{2}{*}{ Sig. } \\
\hline & & & $B$ & STD. error & & \\
\hline \multirow{23}{*}{1} & & (Constant) & 0.083 & 44.827 & & 0.999 \\
\hline & $\begin{array}{l}\text { (1) Distance from nearest } \\
\text { built-up area }\end{array}$ & DFNBA & -0.001 & 0.002 & -0.052 & 0.516 \\
\hline & (2) Altitude/elevation & AL & 0.000 & 0.003 & 0.014 & 0.882 \\
\hline & (3) Slope & SLP & 0.028 & 0.029 & 0.075 & 0.331 \\
\hline & (4) Distance from nearest stream & DFNS & -0.001 & 0.001 & -0.059 & 0.468 \\
\hline & (5) Temperature & TEM & 0.437 & 0.293 & 0.146 & 0.139 \\
\hline & (6) Relative humidity & RH & 0.245 & 0.053 & 0.400 & 0.000 \\
\hline & (7) Light intensity & ILUX & $-8.959 E-05$ & 0.000 & -0.021 & 0.805 \\
\hline & (8) Tree basal area & TBA & -9.269 & 1.566 & -0.660 & 0.000 \\
\hline & (9) Canopy cover & TCPY & 0.021 & 0.006 & 0.261 & 0.001 \\
\hline & (10) Shrub layer & SHBL & 0.073 & 0.043 & 0.156 & 0.090 \\
\hline & (11) No. of trees $(\mathrm{dbh} \geq 10-19)$ & NTB & -0.304 & 1.345 & -0.019 & 0.822 \\
\hline & (12) No. of trees $(\mathrm{dbh} \geq 20-29)$ & NTC & -1.031 & 4.094 & -0.380 & 0.802 \\
\hline & (13) No. of trees $(\mathrm{dbh} \geq 30-39)$ & NTD & -0.525 & 4.141 & -0.130 & 0.899 \\
\hline & (14) No. of trees $(\mathrm{dbh} \geq 40-49)$ & NTE & -0.808 & 4.106 & -0.154 & 0.844 \\
\hline & (15) No. of trees $(\mathrm{dbh} \geq 50-59)$ & NTF & -0.057 & 4.126 & -0.007 & 0.989 \\
\hline & (16) No. of trees $(\mathrm{dbh} \geq 60 \mathrm{~cm})$ & NTG & -0.312 & 4.421 & -0.015 & 0.944 \\
\hline & (17) No. of trees $(<10)$ & NTS & 6.503 & 4.532 & 0.407 & 0.154 \\
\hline & (18) No. of tree $(\geq 10-19)$ & NTT & 0.028 & 0.239 & 0.011 & 0.906 \\
\hline & (19) No. of trees $(\geq 30-39)$ & NTV & 0.000 & 0.362 & 0.000 & 0.999 \\
\hline & (20) No. of trees $(\geq 40-49)$ & NTW & -2.781 & 1.998 & -0.126 & 0.167 \\
\hline & (21) No. of trees $(\geq 50)$ & NTX & -3.495 & 5.669 & -0.047 & 0.539 \\
\hline & (22) Evenness index value & EIV & 18.658 & 23.786 & 0.067 & 0.435 \\
\hline
\end{tabular}

$F(22,107)=4.093$.

Sig. of $F=0.000$.

$R^{2}=0.457$

Adjusted $R^{2}=0.345$.

of regression analysis between the population density of $C$. cebuensis at habitat or landscape level. The final model shows that adjusted $R^{2}=0.345, F(22,107)=4.093, P<0.000$ (using the enter method). By looking at the final model (particularly the adjusted $R^{2}$ value) this shows that only about $34.5 \%$ of the variances of the population density of $C$. cebuensis were being accounted for by the model.

Only three out 25 predictors have been able to explain the behavior of the population density of $C$. cebuensis, namely, (1) relative humidity $(\mathrm{RH})$ and canopy cover (TCPY) having positive high significant correlation (beta) with population density, 0.400 and 0.261 , respectively, with $P$ values at 0.000 and 0.001 with, respectively, which is $<0.01$ significant level. These findings indicate that with high $\mathrm{RH}$ and TCPY the population density of $C$. cebuensis may increase. While tree basal area (TBA) it has a negative high significant correlation with $C$. cebuensis population density with coefficient (beta) value of -0.660 and a $P$ value of 0.000 significant at 0.01 level. This finding indicates that if TBA increases, the population of density of C. cebuensis decreases. The study on insectivorous birds and environmental factors in Malaysia's tropical rainforest showed that terrestrial insectivores were sensitive to forest edge and could indicate the quality of forest interior habitats associated with high humidity, dense canopy cover, and deep litter depth [20].

(4) Regression Analysis between Pooled Population Density Estimates of C. cebuensis and Landscape Variables for Sampling Sites. Based on the multiple linear regression analysis (using enter method) the results have shown a final model of adjusted $R^{2}=0.212, F(10,119)=4.474, P<0.000$ with only 10 predictors included in the final analysis. This indicates that the model has accounted only for $21.2 \%$ of the variation of population density of C. cebuensis which is lower by $13.3 \%$ compared to what is accounted for in the regression done at the habitat level. Table 6 presents the results of the regression done at this level.

It has been observed further that there are four predictors that have explained the behavior of the population density of C. cebuensis, namely, (a) elevation, (b) slope, (c) canopy cover, 
TABLE 6: Results of the regression analysis between pooled population density estimates in four sampling sites (with 10 predictors included in the analysis).

\begin{tabular}{|c|c|c|c|c|c|c|}
\hline \multirow[t]{2}{*}{ Model } & \multirow{2}{*}{ Predictors } & \multirow{2}{*}{ Code } & \multicolumn{2}{|c|}{ Unstandardized coefficients } & \multirow{2}{*}{$\begin{array}{c}\text { Standardized } \\
\text { coefficients } \\
\text { Beta }\end{array}$} & \multirow{2}{*}{ Sig. } \\
\hline & & & $B$ & STD. error & & \\
\hline \multirow{11}{*}{1} & (Constant) & & 85.333 & 27.538 & & 0.002 \\
\hline & (1) Elevation & ELEV & 0.030 & 0.007 & 0.398 & 0.000 \\
\hline & (2) Slope & SLP & -0.148 & 0.068 & -0.178 & 0.032 \\
\hline & (3) Temperature & TEM & 0.651 & 0.680 & 0.097 & 0.341 \\
\hline & (4) Relative humidity & $\mathrm{RH}$ & 0.029 & 0.115 & 0.022 & 0.799 \\
\hline & (5) Light intensity & ILUX & $6.542 E-05$ & 0.001 & 0.007 & 0.938 \\
\hline & (6) Tree density & TDEN & 0.007 & 0.015 & 0.040 & 0.626 \\
\hline & (7) Canopy cover & TCPY & 0.186 & 0.091 & 0.177 & 0.043 \\
\hline & (8) Shrub cover & SHBL & -0.157 & 0.078 & -0.165 & 0.047 \\
\hline & (9) Diameter-at-breast-height & $\mathrm{DBH}$ & -0.106 & 0.241 & -0.046 & 0.660 \\
\hline & (10) Total height & $\mathrm{TH}$ & -0.466 & 0.491 & -0.101 & 0.345 \\
\hline
\end{tabular}

$F(10,119)=4.474$.

Sig. of $F=0.000$.

$R^{2}=0.273$.

Adjusted $R^{2}=0.212$.

and (d) shrub cover. Elevation has positive high significant correlation (beta) with population density of $C$. cebuensis with standardized coefficient of 0.398 and with $P$ value of 0.000 , significant at 0.01 level (Table 6). This means that with increasing elevation the density of population of $C$. cebuensis will likely increase. According to [21] variations in the number of bird occurrences along elevation gradient in the natural and urbanized habitats in western Himalaya, Nainital district of Uttarakhand, India, found out that bird species richness (BSR) varied considerably with elevation. This difference in BSR among study sites could be due to elevation and vegetation differences associated with elevation and not caused by the presence of a group of mid-altitude specialists.

For slope and shrub cover it is negatively correlated with population density of $C$. cebuensis with coefficients of -0.178 and -0.165 and with values of 0.032 and 0.047 , significant at 0.05 level, respectively. These findings indicate that with increasing slope and shrub cover the population density of $C$. cebuensis will likely decrease. Lastly, for canopy cover it had positive significant correlation with $C$. cebuensis population density with coefficient of 0.177 and a $P$ value of 0.043 which is significant at 0.01 level. This means that with increasing canopy cover the population density of C. cebuensis will likely increase.

3.4. Conclusion and Recommendations. AWR is dominated by cultivated land, and forest area at AWR is fragmented and heterogeneous. On the basis of the landscape pattern analysis conducted in AWR using four landscape metrics/indices (shape metric) shows that the landscape pattern in AWR could be characterized as more fragmented and more heterogeneous with patches at classes (especially forest areas) that are increasingly complex and irregular. This condition could affect $C$. cebuensis subpopulations to become more fragmented or isolated. However, results show that C. cebuensis subpopulations are still widespread or widely distributed within these remaining forest patches especially those being sampled.

In regression analysis, there are only three out of 25 and four out of 10 have been able to predict or explain the behavior of the population density of $C$. cebuensis at habitat (landscape) and sampling site levels. Predictors which are positively highly significant at the habitat level were the following: (a) relative humidity $(0.400,0.01<P$ value $=$ $0.000)$ and (b) canopy cover $(0.261,0.01<P$ value $=0.001)$ while tree basal area is negatively highly correlated $(-0.660$, $0.01<P$ value $=0.000)$. At sampling site, elevation has high positive significant correlation $(0.398,0.01<P$ value $=0.000$ ) with $C$. cebuensis population density, and canopy cover has positive significant correlation $(0.177,0.05<P$ value $=0.043)$, whereas slope and shrub cover have negative significant correlation $(-0.178,0.05<P$ value $=0.032$ and $-0.165,0.05<P$ value $=0.047)$. Based on the final model and given the two levels of analysis, at landscape, results have shown that $34.5 \%$ of the variances of the population density of C. cebuensis have been accounted for, while at the sampling site it accounts only for $21.2 \%$.

Study suggested that regression analysis at landscape or habitat level is better than same analysis at sampling site. Study concludes with a series of sound policies and management recommendations to preserve AWR.

3.4.1. Policy Measures to Protect C. cebuensis Native Habitats. Integrating the use of indigenous tree species in rehabilitation and reforestation programs whether it is undertaken by public agencies or private entities within study site to preserve native habitat for C. cebuensis taking into account the remaining forest within the watershed area. Promoting and adopting 
landscape approach in rehabilitating degraded habitats. The Department of Environment and Natural Resources (DENR) may have been practicing this approach in rehabilitating degraded areas. This approach, however, focused on the relationship at various scales from species up to landscape. Each and every element or patch is taken into account as a basic unit of the entire system.

3.4.2. Management Aspect. Management and rehabilitation of remaining forest habitat patches within Argao watershed should be based the findings of landscape pattern analysis conducted in this study. Results show that the higher landscape metric value indicates that the forest patches in Argao watershed were highly fragmented. Institute connections on isolated patches, mainly through corridor establishment using riparian forest, is an excellent option of patches connection is imperative. There is a need to rehabilitate riparian vegetation especially those that are highly degraded and sparsely stocked with vegetation. Results show that most of the contacts with C. cebuensis were in the valley bottom where relative humidity is high due to the presence of vegetation.

3.4.3. Further Research on Copsychus cebuensis. Follow-up study on the foraging behavior of the target species to ascertain more on the type of insects being preyed about. Follow-up study on the effect of patch area on the population density and/or abundance of the target species. This study was able to survey selected forest habitat patches within AWR. However, the effect of the patch area with the population density of $C$. cebuensis has not been explored.

Continue the monitoring populations in all forest patches in Argao watershed to quantify all existing subpopulations. Since this study had covered only limited number of the remaining forest patches within Argao watershed, it is advised to continue monitor all the forest patches within the area to be able to quantify all existing subpopulations.

\section{Acknowledgments}

Thanks are due to the generous funders of this research study: the Department of Science and Technology through the Accelerated Science and Technology Human Resource Development Program (ASTHRDP), Philippines Council for Agriculture, Aquatic and Natural Resources Research and Development (PCAARRD) of the Department of Science and Technology, and the National Mapping and Resource Information Administration (NAMRIA) for providing the satellite image (SPOT-5) used in the landscape pattern analysis.

\section{References}

[1] A. Soffianian, S. M. Najafabadi, and V. Rahdari, "Quantifying landscape pattern using RS \& GIS techniques for mooteh wildlife refuge," JWSS - Isfahan University of Technology, vol. 13, no. 49, pp. 141-150, 2009.

[2] A. B. B. Malaki and I. E. Buot Jr., "Conservation status of indigenous trees in Argao river watershed reserve, Cebu Island, Philippines," Asia Life Sciences, vol. 20, supplement 6, pp. 45-59, 2011.
[3] BirdLife International, "Species Factsheet: Copsychus cebuensis," 2012, http://www.birdlife.org/.

[4] Community Environment and Natural Resources Office, FiveYear Development Plan of Argao River Watershed Reserve (ARWR), Community Environment and Natural Resources Office, Cebu, Philippines, 2003.

[5] K. Mcgarigal and B. J. Marks, Spatial Pattern Analysis Program for Quantifying Landscape Structure, Forest Science Department, Oregon State University, Corvallis, Ore, USA, 1995.

[6] C. Bibby, M. Jones, and S. Marsden, Expedition Field Techniques: Bird Surveys, Birdlife International, Cambridge, UK, 2000.

[7] Z. Rosli, M. Zakaria, A. Mohd, A. Yusuf, G. James, and A. Khairulmazmi, "Response of upperstory birds to the environmental variables at different distances from the edge of an isolated forest reserve in Malaysia," Asia Life Sciences Journal, vol. 21, no. 1, pp. 65-84, 2012.

[8] M. R. C. Posa and N. S. Sodhi, "Effects of anthropogenic land use on forest birds and butterflies in Subic Bay, Philippines," Biology Conservation, vol. 129, no. 2, pp. 256-271, 2006.

[9] R. S. Kennedy, P. C. Gonzales, E. C. Dickinson, H. Miranda, and T. H. Fisher, A Guide to the Birds of the Philippines, Oxford University Press, New York, NY, USA, 1st edition, 2000.

[10] C. E. Shannon and W. Weaver, The Mathematical Theory of Communication, University of Illinois Press, Urbana, Ill, USA, 1949.

[11] G. O. Cadiz and I. E. Buot Jr., "A checklist of the vascular plants of the mount Tabunan, Cebu, Island, Philippines," Thailand Natural History Museum Journal. In press.

[12] P. G. Jakosalem and L. M. Paguntalan, "Strengthened Community-Based Biodiversity Conservation in Selected Sites of Cebu, Philippines "Siloy Project 2007'”, Project update (RSG Ref:40. 02. 07), The Ruffourd Small Grant Foundation, 2007, http://www.ruffordsmallgrants.org/.

[13] Environmental Systems Research Institute (ESRI), Inc., ArcInfo Version 10 Deskstop, Environmental Systems Research Institute (ESRI), Inc., Redlands, Calif, USA, 2010.

[14] R. S. Rempel, A. P. Carr, and D. Kaukinen, Patch Analyst Extension for ArcMap: Version 4.2, Ontario Ministry of Natural Resources, Ontario, Canada, 2008.

[15] S. J. Marsden, M. Whiffin, and M. Galetti, "Bird diversity and abundance in forest fragments and Eucalyptus plantations around an Atlantic forest reserve, Brazil," Biodiversity and Conservation, vol. 10, no. 5, pp. 737-751, 2001.

[16] Municipal Development Planning Office, Annual Report. Municipality of Argao, Municipal Development Planning Office, Cebu, Philippines, 2010.

[17] Municipal Development Planning Office, Annual. Municipality of Dalaguete, Cebu, 2010.

[18] National Statistics Office, The 2010 Census of Population and Housing, National Statistics Office, Manila, Philippines, 2010.

[19] A. Ibarra-Macias, W. D. Robinson, and M. S. Gaines, "Experimental evaluation of bird movements in a fragmented neotropical landscape," Biological Conservation, vol. 144, no. 2, pp. 703712, 2011.

[20] H. V. Moradi, M. Zakaria, A. B. Mohd, and E. Yusof, "Insectivorous birds and environmental factors across an edge-interior gradient in tropical rainforest of Malaysia," International Journal of Zoological Research, vol. 5, no. 1, pp. 27-41, 2009.

[21] D. Bhatt and K. K. Joshi, "Bird assemblages in natural and urbanized habitats along elevational gradient in nainital district (Western Himalaya) of Uttarakhand State, India," Current Zoology, vol. 57, no. 3, pp. 318-329, 2011. 

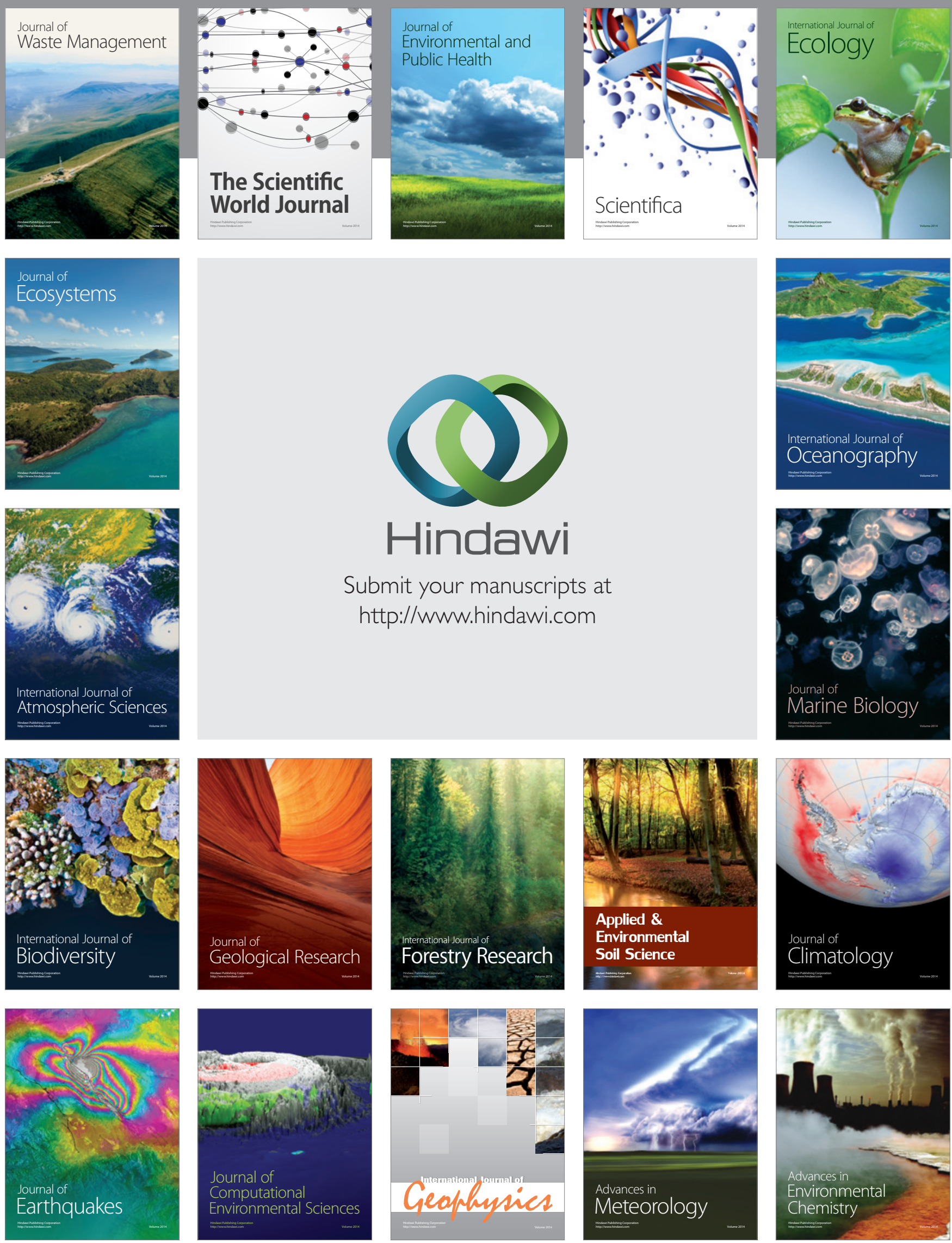